\title{
A comparison of laparoscopy versus laparotomy for the management of adnexal masses during pregnancy over the last 16 years: retrospective study
}

\author{
Zhiqiang Zhang \\ Beijing Chaoyang Hospital affiliated to Capital Medical University \\ Boran Mu \\ Beijing Chao-Yang Hospital affiliated to Capital Medical University \\ Jinhua Leng \\ Peking Union Medical College Hospital \\ Menghui Li ( $\sim$ onlyjiaozi@126.com ) \\ Beijing Chao-Yang Hospital: Beijing Chaoyang Hospital
}

Research

Keywords: laparoscopy, laparotomy, adnexal mass, pregnancy outcomes

Posted Date: May 3rd, 2021

DOl: https://doi.org/10.21203/rs.3.rs-328237/v1

License: (c) (1) This work is licensed under a Creative Commons Attribution 4.0 International License.

Read Full License 


\section{Abstract \\ Background}

Adnexal masses during pregnancy is not rare. More and more evidences imply that operative laparoscopy for adnexal masses performed during pregnancy could be safe and feasible. We procured and evaluated the surgical, obstetric outcomes between laparoscopy and laparotomy for the management of adnexal masses during first and second trimester period in our hospital.

\section{Results}

117 pregnant women with adnexal masses were treated by laparoscopy (69 cases) or laparotomy (48 cases) between July 2003 and March 2019. The laparoscopy group had a significantly lower blood loss $(22.0 \pm 3.4 \mathrm{ml}$ vs $41.7 \pm 4.3 \mathrm{ml}, \mathrm{P}=0.0004)$, a shorter onset of flatus after operation $(24.2 \pm 0.1 \mathrm{~h}$ vs $41.6 \pm$ $1.9 \mathrm{~h}, \mathrm{P}<0.0001)$ and a shorter hospital stay $(3.5 \pm 0.2$ days vs $6.6 \pm 0.2$ days, $<0.0001)$ than the laparotomy group. No patient from either group required a blood transfusion. There is no significant difference in obstetric outcomes, including preterm labor and fetal loss. The median follow-up time was 3.5 years (range, 1.5-11.5 years) after surgery. The median age of the children was 2.5 years (range, 19.5 years). No notable abnormality was found.

\section{Conclusions}

In this retrospective study, compared with laparotomy, laparoscopy has successful outcome with lower blood loss, shorter onset of flatus after surgery, and shorter hospital stay, all of those suggest that operative laparoscopy could be promising for adnexal masses performed during pregnancy.

\section{Background}

Adnexal masses during pregnancy is reported with incidence ranges from 1 in 81 to 1 in 8000 pregnancies ${ }^{[1]}$. Based on an increased rate of spontaneous resolution for adnexal masses $\leq 6 \mathrm{~cm}$ in greatest diameter, expectant management is the first-choice of treatment. However, in the presence of a persistent or symptomatic adnexal mass and/or larger than $6 \mathrm{~cm}$ in greatest diameter, surgical management is not disputed, considering the risk of major complications such as torsion, rupture, bleeding, or malignancy $(1-8 \%)[2,3]$.

Laparoscopic management of adnexal masses in pregnancy is technically feasible ${ }^{[2,4-7]}$. The American College of Obstetricians and Gynecologists (ACOG) Committee reported the specific recommendations, which laparoscopy is currently accepted as the most efficient method to manage adnexal masses in pregnancy when surgery is indicated ${ }^{[8]}$. The role of laparoscopy has been a great debate recently in the management of adnexal masses in pregnancy ${ }^{[9]}$, it has decreased post-operative pain, less narcotic use, 
shorter hospital stays, and less uterine irritability ${ }^{[1]}$. Furthermore, laparoscopy could be very important in decreasing thrombotic events by faster post-operative ambulation and return to regular activity.

The main purpose of our study was to investigate and compare the pregnancy outcomes of laparoscopic or laparotomy management in ovarian tumors during first and second trimester period, including operative time, bleeding volume, onset of flatus after surgery, hospital stay, fetal loss rate, premature delivery rate.

\section{Results}

A total of 69 patients have been treated by laparoscopy and 49 patients by laparotomy, and the patients characteristics, including age, gestational age at the time of operation, ultrasound volume of mass, interval (consultation to operate), level of CA125, gestational age at birth and birth weight of the fetus were not significantly different. (Table 1 ).

Table 1

Characteristics of the patients who underwent laparoscopy or laparotomy.

\begin{tabular}{|c|c|c|c|}
\hline & $\operatorname{lap}(n=69)$ & $\operatorname{LAT}(n=48)$ & $\mathbf{P}$ \\
\hline Age(years, Mean \pm SD) & $28.4 \pm 0.5$ & $26.7 \pm 0.6$ & $0.9102 \dagger$ \\
\hline Gravidity & $1.7 \pm 0.1$ & $1.5 \pm 0.1$ & $0.1800 t$ \\
\hline Mass size (cm) & $8.2 \pm 0.4$ & $9.4 \pm 0.4$ & $<0.0219 \dagger$ \\
\hline Interval(consultation to operate)(months) & $7.4 \pm 2.9$ & $4.7 \pm 1.6$ & $0.4866+$ \\
\hline Bilaterality of mass $(n, \%)$ & 11(15.9) & $8(16.7)$ & $0.7565 \ddagger$ \\
\hline \multicolumn{4}{|l|}{ CA125(U/mL) } \\
\hline Mean \pm SD & $63.5 \pm 17.1$ & $48.4 \pm 7.3$ & $0.5527 \dagger$ \\
\hline Range & $8.4-272.6$ & $26.7-89.3$ & \\
\hline \multicolumn{4}{|l|}{ gestational age at birth(weeks) } \\
\hline Mean \pm SD & $39.0 \pm 0.25$ & $39.0 \pm 0.34$ & $0.9341+$ \\
\hline Range & $37.0-41.0$ & $35.0-41.0$ & \\
\hline Birth weight $(g$, Mean \pm SD) & $3345 \pm 78.58$ & $3144 \pm 102.9$ & $0.1408+$ \\
\hline Prior caesarean delivery $(n, \%)$ & $17(24.6)$ & $6(12.5)$ & $0.0218 \ddagger$ \\
\hline
\end{tabular}

All the operations were performed successfully with no complications. The laparoscopy group had a significantly earlier mean gestational age at surgery and a significantly lower rate of undergoing 
emergency surgery compared with the laparotomy group. The emergency surgery rate of laparotomy group was higher than that of laparoscopy group (54.2\% vs $26.1 \%$ ). The indications for laparoscopic surgery and laparotomy were persistent pelvic cyst in 51 (73.9\%) cases and $22(45.8 \%)$ cases, torsion of adnexa in $12(17.4 \%)$ cases and $23(47.9 \%)$ cases, and rupture of ovarian cysts with internal bleeding in 6 $(8.7 \%)$ case and $3(6.3 \%)$ cases, respectively. The laparoscopy group had a lower blood loss $(22.0 \pm 3.4 \mathrm{ml}$ vs $41.7 \pm 4.3 \mathrm{ml}$ ), a shorter onset of flatus after operation ( $24.2 \pm 1.0$ hours vs $41.6 \pm 1.9$ hours), and a shorter length of hospital stay ( $3.5 \pm 0.2$ days vs $6.6 \pm 0.2$ days) than the laparotomy group. (Table 2$)$. For further analysis, laparoscopy has the similar results in blood loss, onset of flatus, and hospital stay, considering the different trimester. (Table 3). All the patients had an uneventful recovery.

Table 2

Surgical outcome of the patients who underwent laparoscopy or laparotomy.

\begin{tabular}{|c|c|c|c|}
\hline Surgical outcome & $\operatorname{lap}(n=69)$ & $\operatorname{LAT}(n=48)$ & $\mathbf{P}$ \\
\hline Gestation age at operation(weeks, Mean \pm SD) & $13.7 \pm 0.4$ & $15.5 \pm 0.9$ & $<0.0379 \dagger$ \\
\hline Range & $5.0-20.0$ & $7.0-31.0$ & \\
\hline Emergency surgery (n, \%) & $18(26.1)$ & $26(54.2)$ & $<0.0038 \ddagger$ \\
\hline Torsion & $12(17.4)$ & $23(47.9)$ & \\
\hline Rupture & $6(8.7)$ & $3(6.3)$ & \\
\hline Operation time (minutes, Mean \pm SD) & $69.3 \pm 5.1$ & $72.3 \pm 4.3$ & $0.6795+$ \\
\hline blood loss $(m l$, Mean \pm SD $)$ & $22.0 \pm 3.4$ & $41.7 \pm 4.3$ & $0.0004 \dagger$ \\
\hline Onset of flatus after operation(hours, Mean \pm SD) & $24.2 \pm 1.0$ & $41.6 \pm 1.9$ & $<0.0001 \dagger$ \\
\hline hospital stay (days, Mean \pm SD) & $3.5 \pm 0.2$ & $6.6 \pm 0.2$ & $<0.0001 \dagger$ \\
\hline \multicolumn{4}{|l|}{ Surgical procedures $(\mathrm{n}, \%)$} \\
\hline Cystectomy & $62.0(89.9)$ & $36(75.0)$ & \multirow[t]{2}{*}{$0.0082 \ddagger$} \\
\hline Salpingo-ophorectomy & $5.0(7.2)$ & $12(25.0)$ & \\
\hline Detorsion & $2(2.9)$ & $0(0.0)$ & \\
\hline
\end{tabular}


Table 3

Surgical outcome of the patients who underwent laparoscopy or laparotomy by trimester of pregnancy.

\begin{tabular}{|c|c|c|c|c|c|}
\hline & \multicolumn{2}{|c|}{ Laparoscopy $(n=69)$} & \multicolumn{2}{|c|}{ Laparotomy $^{*}(n=48)$} & \multirow[t]{2}{*}{$P$ value } \\
\hline & $\begin{array}{l}\text { First }(n= \\
22)\end{array}$ & $\begin{array}{l}\text { Second }(n= \\
47)\end{array}$ & $\begin{array}{l}\text { First }(n= \\
16)\end{array}$ & $\begin{array}{l}\text { Second }(n= \\
32)\end{array}$ & \\
\hline Age (years) & $28.6 \pm 0.8$ & $28.3 \pm 0.6$ & $26.2 \pm 0.9$ & $26.9 \pm 0.8$ & $0.1618^{*}$ \\
\hline $\begin{array}{l}\text { GW at operation } \\
\text { (weeks) }\end{array}$ & $9.2 \pm 0.5$ & $15.7 \pm 0.3$ & $9.3 \pm 0.5$ & $18.6 \pm 0.8$ & <.0001* \\
\hline Mass size $(\mathrm{cm})$ & $7.3 \pm 0.6$ & $8.6 \pm 0.4$ & $9.1 \pm 0.5$ & $9.6 \pm 0.5$ & $0.0301^{*}$ \\
\hline Operational time (min) & $67.7 \pm 7.9$ & $70.1 \pm 6.6$ & $87.8 \pm 10.1$ & $64.5 \pm 3.5$ & $0.2353^{*}$ \\
\hline Blood loss (ml) & $18.4 \pm 4.4$ & $23.7 \pm 4.5$ & $40.3 \pm 8.4$ & $42.2 \pm 5.2$ & $0.0057^{*}$ \\
\hline Flatus time (hours) & $23.1 \pm 1.3$ & $24.2 \pm 1.3$ & $39.9 \pm 2.1$ & $42.5 \pm 2.7$ & $\dot{0.0001 *}$ \\
\hline Hospital stay (days) & $3.6 \pm 0.3$ & $3.5 \pm 0.2$ & $7.1 \pm 0.5$ & $6.3 \pm 0.2$ & $<.0001^{*}$ \\
\hline
\end{tabular}

The most common histopathological diagnosis was benign cystic teratoma in $33.8 \%(46 / 136)$ of cases. The distributions of pathology differed between groups, in particular, the rate of malignant mass was higher in the laparotomy group (8.9\%) than in the laparoscopy group (0.0\%) (Table 4). Pregnancy was continued to term in 116 patients $(99.1 \%)$. Only 1 patient in laparotomy group delivered at $35^{+2}$ gestational weeks. There was no significant difference in gestational age at birth and birth weight between groups. No preterm labor was reported in laparoscopy group. All the babies were healthy. 
Table 4

Pathologic diagnoses (\%) of the patients who underwent laparoscopy or laparotomy.

\begin{tabular}{|llll|}
\hline Pathologic diagnosis & lap(n= 78) & LAT $(\mathbf{n}=\mathbf{5 6})$ & Total( $\mathbf{n}=\mathbf{1 3 4})$ \\
\hline Mature cystic teratoma & $27(34.6)$ & $19(33.9)$ & $46(34.3)$ \\
\hline Corpus luteum & $18(23.1)$ & $9(16.1)$ & $27(20.1)$ \\
\hline Mucinous cystadenoma & $4(5.1)$ & $6(10.7)$ & $10(7.5)$ \\
\hline Endometriosis & $3(3.8)$ & $1(1.8)$ & $4(3.0)$ \\
\hline Serous cystadenoma & $5(6.4)$ & $4(7.1)$ & $9(6.7)$ \\
\hline Paraovarian cyst & $8(10.3)$ & $7(12.5)$ & $15(11.2)$ \\
\hline Follicular cyst & $1(1.3)$ & $1(1.8)$ & $2(1.5)$ \\
\hline Paratubal cyst & $4(5.1)$ & $1(1.8)$ & $5(3.7)$ \\
\hline Malignant mass & & & $2(1.5)$ \\
\hline Borderline mucinous mass & 0 & $2(3.6)$ & $1(0.7)$ \\
\hline Borderline serous mass & 0 & $1(1.8)$ & 0 \\
\hline Mucinous adenocarcinoma & 0 & & $2(1.5)$ \\
\hline Immature teratoma & 0 & $2(3.6)$ & 0 \\
\hline Invasive serous mass & 0 & & $8(6.0)$ \\
\hline Endometriod adenocarcinoma & $8(10.3)$ & $3(5.3)$ & 0 \\
\hline Not determined & & & \\
\hline $\begin{array}{l}\text { †Tissue of adnexal masses was not obtained during operations including release of the torsion, or } \\
\text { exploration of pelvic cavity. }\end{array}$ & & & \\
\hline
\end{tabular}

\section{Discussion}

The results of our study show that, comparing to laparotomy, laparoscopic surgery in pregnancy has a significantly earlier gestational age at surgery, a significantly lower rate of undergoing emergency surgery, a lower blood loss, a shorter onset of flatus after operation, and a shorter hospital stay. No significant difference in fetal loss and preterm labor was observed between the two groups.

A concern of the laparoscopy during pregnancy is the timepoint of performing procedure. The recommended timepoint for laparoscopic intervention of adnexal mass is between 16 and 20 weeks of gestation ${ }^{[11]}$. Not only because it does not give time for the mass to resolve on its own, but also because of the possibly compromising ovarian hormone production before the placenta is fully functional. In our study, 22 cases in laparoscopy and 16 cases in laparotomy were performed in the first trimester 
respectively, and the indications for procedure were acute pelvic pain in which cyst torsion was demonstrated during procedure and persistent cyst with solid portion. Increasing studies have been

published attesting to the safety of laparoscopic operation during early pregnancy ${ }^{[12-14]}$. Postponing necessary operations until after parturition may increase the rates of complications for mother and fetus.

An additional concern unique to laparoscopic surgery is the effect of the pneumoperitoneum on compromising uterine blood flow, resulting in fetal hypoxia and acidemia, injection of carbon dioxide into the amniotic cavity, and the potential for acidosis in the fetal environment because of maternal conversion of carbon dioxide into carbonic acid. Reedy MB et al ${ }^{[16]}$ demonstrated that there were no significant differences in birth weight, gestational duration, intra-uterine growth restriction, infant death, or fetal malformation for patients undergoing laparoscopy versus laparotomy in singleton pregnancies between 4 and 20 weeks of gestation. Candiani $M$ et al ${ }^{[17]}$ recently showed that the uteroplacental perfusion and the umbilical artery pulsatility index did not change significantly during the laparoscopic procedure evaluated using noninvasive ultrasonography in human pregnancy.

Considering the risk of preterm labor and fetal loss, many reports has been discussed the relative safety of laparoscopy compared with open surgery in pregnancy ${ }^{[18]}$. No significant difference in fetal loss and preterm labor was observed between the two groups in our report. It was reported that two newborns had congenital malformation (hypospadia, cleft lip and palate) in 39 patients underwent laparoscopy operative treatment of adnexal masses during pregnancy in the first trimester of pregnancy ${ }^{[19]}$. Whether surgery related to these anomalies is unknown.

The properly operational gestation, indication, and the surgical techniques could be associated with the acceptable outcomes of our series. The surgical techniques include patient positioning in a left lateral decubitus position, initial port placement altering from the standard configuration to account for the increased size of the uterus, insufflations pressure of lower than $15 \mathrm{mmHg}$, and bipolar used for hemostasis were recommended ${ }^{[12]}$. In the procedures, the location of the first Trocar is very important, also is very dangerous because of the insertion with blind, it is recommended to adjust according to fundal height, involving the umbilical or supraumbilical area, or subxyphoid insertion of the Trocar, with at least $6 \mathrm{~cm}$ between the point of entry and the top of the fundus. Besides that, intra-abdominal pressure during the surgery should be kept below $12 \mathrm{~mm} \mathrm{Hg}$ to ensure adequate venous return and uteroplacental blood flow, with the patient in Trendelenburg position.

\section{Conclusions}

More and more evidences, including the results of our study, imply that operative laparoscopy with a lower blood loss, a shorter onset of flatus after surgery and a shorter hospital stay, for adnexal masses performed during pregnancy could be safe and feasible. The pregnancy and neonatal outcomes in our series patients are promising. Procedures in the second trimester without emergency indications is preferable, intervene should be done before the second trimester with any sign of malignancy or emergency. 


\section{Methods}

In a 16 year period from July 2013 to March 2019, the hospital records of female patients that underwent procedure by laparoscopy or laparotomy for benign adnexal masses during pregnancy were retrospectively reviewed, after approval by the institutional review board the study. The hospital records of patients included the demographic characteristics (gravidity and parity), gestational weeks at diagnosis and at surgery, signs and symptoms, pathology reports, complications of surgery, and the pregnancy outcome.

The indications for surgery included symptomatic adnexal masses, persistent or enlarging masses or suspicion of malignancy on sonography. In cases of nonsymptomatic women and a lack of clinical suspicion of a malignant mass, surgical management was generally performed when the mass was larger than $6 \mathrm{~cm}$ or persistent until 16 weeks of gestation. Patients who had a viable intrauterine embryo and a desire to continue the pregnancy were included. Patients with heterotopic pregnancies or malignancy, and or with induced abortion concomitantly, and or with incomplete medical records were excluded.

Laparoscopic procedure was performed with the patient under general anesthesia and endotracheal incubation. As for the surgical technique, the patients were placed slowly and carefully in dorsal supine position. Abdominal insufflations were done by inserting the Veress needle in the umbilical or supraumbilical area, the location of which is adjusted according to fundal height. The first Trocar which was 10 -mm was inserted below the umbilicus. Pneumoperitoneum was established with use of $\mathrm{CO} 2$ insufflations and was maintained at an intra-abdominal pressure of $12 \mathrm{~mm} \mathrm{Hg}$. The second and third Trocar was then placed under direct vision to avoid injury to the uterus. Bipolar was used for hemostasis. The decision for cystectomy, oophorectomy, and detorsion operation depended on the surgical findings. The specimens were removed. A case-by-case administration of prophylactic antibiotics preoperatively or postoperatively was done, and not routinely.

Laparotomy was performed under general or regional anesthesia, based on the surgeon's preference. Open surgery was performed in the standard fashion. A low midline or Pfannenstiel skin incision was made based on mass size, preoperative scarring or the surgeon's preference. After surgery, the patients were not commonly given acetaminophen as analgesia. Patients who became pregnant within 12 months were given progesterone $20 \mathrm{mg}$ twice a day till 12 weeks ${ }^{[10]}$. Fetal well-being was assessed again routinely before discharge. Patients were allowed to discharge when they were fully mobile, passing urine satisfactorily, and not requiring narcotic analgesia.

Follow-up was done for all patients. For those patients who delivered in our institution, pregnancy outcome was obtained from their medical records. For those patients who delivered elsewhere, three attempts were made to collect that information by telephone. Those cases in which information was received by telephone, the patients were asked to deliver the information from the official birth documents to minimize the effect of recall bias. 
GraphPad Prism 7.0 (GraphPad Software, La Jolla, CA, USA) was used for all statistical analyses. Student's t-test and the one-way ANOVA were used to compare the continuous variables and the categorical data, respectively. $\mathrm{P}<0.05$ was considered as statistically significant.

\section{Declarations}

\section{Ethics approval and consent to participate}

This study protocol was approved by the Institutional Review Board (IRB) of Beijing Chao-Yang Hospital affiliated to Capital Medical University (IRB no. 2016-science-166). All patients received information on the purpose and conduct of this study, and provided written, informed consent.

\section{Consent to publication}

The written informed consent was acquired from the patient for this publication and is available for review by the editor of this journal.

\section{Availability of data and materials}

All data generated or analyzed during this study are included in this published article.

\section{Competing interests}

The authors declare that they have no conflict of interest.

\section{Funding}

This work was supported by National key R\&D Program of China Number: 2017 YFC1001200.

\section{Authors' contributions}

M.H.Li performed the surgery, conceived and designed the study, analyzed the data, contributed materials/analysis tools, and wrote the paper. Zh.Q.Zh collected analyzed the data, contributed materials/analysis tools, and wrote the paper. B.R.M recruited the patients, performed the surgery, collected the data, and wrote the paper. J.H.L performed the surgery, recruited the patients. All authors read and approved the final manuscript.

\section{Acknowledgements}

Not applicable.

\section{References}

[1] Leiserowitz GS. Managing ovarian masses during pregnancy. Obstet Gynecol Surv. 2006. 61(7): 463470. 
[2] Whiteside JL, Keup HL. Laparoscopic management of the ovarian mass: a practical approach. Clin Obstet Gynecol. 2009. 52(3): 327-334.

[3] D'Ambrosio V, Brunelli R, Musacchio L, et al. Adnexal masses in pregnancy: an updated review on diagnosis and treatment. Tumori. 2020: 300891620909144.

[4] Mathevet P, Nessah K, Dargent D, Mellier G. Laparoscopic management of adnexal masses in pregnancy: a case series. Eur J Obstet Gynecol Reprod Biol. 2003. 108(2): 217-222.

[5] Boughizane S, Naifer R, Hafsa A, et al. [Laparoscopic management of adnexal tumors after the first trimester of pregnancy]. J Gynecol Obstet Biol Reprod (Paris). 2004. 33(4): 319-324.

[6] Shigemi D, Aso S, Matsui H, Fushimi K, Yasunaga H. Safety of Laparoscopic Surgery for Benign Diseases during Pregnancy: A Nationwide Retrospective Cohort Study. J Minim Invasive Gynecol. 2019. 26(3): 501-506.

[7] Chohan L, Nijjar JB. Minimally Invasive Surgery in Pregnancy. Clin Obstet Gynecol. 2020. 63(2): 379391.

[8] ACOG Committee Opinion No. 775: Nonobstetric Surgery During Pregnancy. Obstet Gynecol. 2019. 133(4): e285-e286.

[9] Ye P, Zhao N, Shu J, et al. Laparoscopy versus open surgery for adnexal masses in pregnancy: a metaanalytic review. Arch Gynecol Obstet. 2019. 299(3): 625-634.

[10] Argenta PA, Yeagley TJ, Ott G, Sondheimer SJ. Torsion of the uterine adnexa. Pathologic correlations and current management trends. J Reprod Med. 2000. 45(10): 831-836.

[11] Fatum M, Rojansky N. Laparoscopic surgery during pregnancy. Obstet Gynecol Surv. 2001. 56(1): 5059.

[12] Jackson H, Granger S, Price R, et al. Diagnosis and laparoscopic treatment of surgical diseases during pregnancy: an evidence-based review. Surg Endosc. 2008. 22(9): 1917-1927.

[13] Ko ML, Lai TH, Chen SC. Laparoscopic management of complicated adnexal masses in the first trimester of pregnancy. Fertil Steril. 2009. 92(1): 283-287.

[14] Zou G, Xu P, Zhu L, Ding S, Zhang X. Comparison of subsequent pregnancy outcomes after surgery for adnexal masses performed in the first and second trimester of pregnancy. Int J Gynaecol Obstet. 2020. 148(3): 305-309.

[15] Cohen SB, Watad H, Shapira M, Goldenberg M, Mashiach R. Urgent Laparoscopic Surgeries during the Third Trimester of Pregnancy: A Case Series. J Minim Invasive Gynecol. 2019. 27(4): 909-914. 
[16] Reedy MB, Kallen B, Kuehl TJ. Laparoscopy during pregnancy: a study of five fetal outcome parameters with use of the Swedish Health Registry. Am J Obstet Gynecol. 1997. 177(3): 673-679.

[17] Candiani M, Maddalena S, Barbieri M, Izzo S, Alberico D, Ronzoni S. Adnexal masses in pregnancy: fetomaternal blood flow indices during laparoscopic surgery. J Minim Invasive Gynecol. 2012. 19(4): 443447.

[18] Liu YX, Zhang Y, Huang JF, Wang L. Meta-analysis comparing the safety of laparoscopic and open surgical approaches for suspected adnexal mass during the second trimester. Int J Gynaecol Obstet. 2017. 136(3): 272-279.

[19] Soriano D, Yefet Y, Seidman DS, Goldenberg M, Mashiach S, Oelsner G. Laparoscopy versus laparotomy in the management of adnexal masses during pregnancy. Fertil Steril. 1999. 71(5): 955-960.

\section{Tables}

Table 1 Characteristics of the patients who underwent laparoscopy or laparotomy.

\begin{tabular}{|c|c|c|c|}
\hline & $\operatorname{lap}(n=69)$ & $\mathrm{LAT}(\mathrm{n}=48)$ & $\mathrm{P}$ \\
\hline Age(years, Mean \pm SD) & $28.4 \pm 0.5$ & $26.7 \pm 0.6$ & $0.9102 \dagger$ \\
\hline Gravidity & $1.7 \pm 0.1$ & $1.5 \pm 0.1$ & $0.1800 \dagger$ \\
\hline Mass size $(\mathrm{cm})$ & $8.2 \pm 0.4$ & $9.4 \pm 0.4$ & $<0.0219 \dagger$ \\
\hline Interval(consultation to operate)(months) & $7.4 \pm 2.9$ & $4.7 \pm 1.6$ & $0.4866 \dagger$ \\
\hline Bilaterality of mass (n, \%) & $11(15.9)$ & $8(16.7)$ & $0.7565 \neq$ \\
\hline \multicolumn{4}{|l|}{$\mathrm{CA} 125(\mathrm{U} / \mathrm{mL})$} \\
\hline Mean \pm SD & $63.5 \pm 17.1$ & $48.4 \pm 7.3$ & $0.5527 \dagger$ \\
\hline Range & $8.4-272.6$ & $26.7-89.3$ & \\
\hline \multicolumn{4}{|l|}{ gestational age at birth(weeks) } \\
\hline Mean \pm SD & $39.0 \pm 0.25$ & $39.0 \pm 0.34$ & $0.9341 \dagger$ \\
\hline Range & $37.0-41.0$ & $35.0-41.0$ & \\
\hline Birth weight $(g$, Mean \pm SD) & $3345 \pm 78.58$ & $3144 \pm 102.9$ & $0.1408+$ \\
\hline Prior caesarean delivery $(n, \%)$ & $17(24.6)$ & $6(12.5)$ & $0.0218 \neq$ \\
\hline
\end{tabular}

†Based on Student’s t-test. $¥ B a s e d$ on Chi-square test.

Table 2 Surgical outcome of the patients who underwent laparoscopy or laparotomy. 


\begin{tabular}{|c|c|c|c|}
\hline$\overline{\text { Surgical outcome }}$ & $\operatorname{lap}(\mathrm{n}=69)$ & LAT $(n=48)$ & $\overline{\mathrm{P}}$ \\
\hline Gestation age at operation (weeks, Mean \pm SD) & $13.7 \pm 0.4$ & $15.5 \pm 0.9$ & $<0.0379 \dagger$ \\
\hline $\begin{array}{l}\text { Range } \\
\end{array}$ & $5.0-20.0$ & $7.0-31.0$ & \\
\hline Emergency surgery $(\mathrm{n}, \%)$ & $18(26.1)$ & $26(54.2)$ & $<0.0038 \neq$ \\
\hline Torsion & $12(17.4)$ & $23(47.9)$ & \\
\hline Rupture & $6(8.7)$ & $3(6.3)$ & \\
\hline Operation time (minutes, Mean \pm SD) & $69.3 \pm 5.1$ & $72.3 \pm 4.3$ & $0.6795 \dagger$ \\
\hline blood loss $(\mathrm{ml}$, Mean \pm SD) & $22.0 \pm 3.4$ & $41.7 \pm 4.3$ & $0.0004 \dagger$ \\
\hline Onset of flatus after operation $\square$ hours, Mean $\pm \mathrm{SD} \square$ & $24.2 \pm 1.0$ & $41.6 \pm 1.9$ & $<0.0001 \dagger$ \\
\hline hospital stay $\llbracket$ days, Mean \pm SD $\square$ & $3.5 \pm 0.2$ & $6.6 \pm 0.2$ & $<0.0001 \dagger$ \\
\hline \multicolumn{4}{|l|}{ Surgical procedures (n, \%) } \\
\hline Cystectomy & $62.0(89.9)$ & $36(75.0)$ & \multirow[t]{2}{*}{$0.0082 \ddagger$} \\
\hline Salpingo-ophorectomy & $5.0(7.2)$ & $12(25.0)$ & \\
\hline Detorsion & $2(2.9)$ & $0(0.0)$ & \\
\hline
\end{tabular}

†Based on Student’s t-test $¥ B a s e d$ on Chi-square test.

Table 3 Surgical outcome of the patients who underwent laparoscopy or laparotomy by trimester of pregnancy.

\begin{tabular}{|c|c|c|c|c|c|}
\hline & \multicolumn{2}{|c|}{ Laparoscopy $(\mathrm{n}=69)$} & \multicolumn{2}{|c|}{ Laparotomy $^{*}(\mathrm{n}=48)$} & \multirow[t]{2}{*}{$\mathrm{P}$ value } \\
\hline & First $(n=22)$ & Second $(n=47)$ & First(n=16) & Second $(n=32)$ & \\
\hline Age (years) & $28.6 \pm 0.8$ & $28.3 \pm 0.6$ & $26.2 \pm 0.9$ & $26.9 \pm 0.8$ & 0.1618* \\
\hline GW at operation (weeks) & $9.2 \pm 0.5$ & $15.7 \pm 0.3$ & $9.3 \pm 0.5$ & $18.6 \pm 0.8$ & $<0.0001^{*}$ \\
\hline Mass size $(\mathrm{cm})$ & $7.3 \pm 0.6$ & $8.6 \pm 0.4$ & $9.1 \pm 0.5$ & $9.6 \pm 0.5$ & $0.0301 *$ \\
\hline Operational time (min) & $67.7 \pm 7.9$ & $70.1 \pm 6.6$ & $87.8 \pm 10.1$ & $64.5 \pm 3.5$ & $0.2353^{*}$ \\
\hline Blood loss (ml) & $18.4 \pm 4.4$ & $23.7 \pm 4.5$ & $40.3 \pm 8.4$ & $42.2 \pm 5.2$ & $0.0057 *$ \\
\hline Flatus time (hours) & $23.1 \pm 1.3$ & $24.2 \pm 1.3$ & $39.9 \pm 2.1$ & $42.5 \pm 2.7$ & $<0.0001^{*}$ \\
\hline Hospital stay (days) & $3.6 \pm 0.3$ & $3.5 \pm 0.2$ & $7.1 \pm 0.5$ & $6.3 \pm 0.2$ & $<0.0001^{*}$ \\
\hline
\end{tabular}

*one-way ANOVA

Table 4 Pathologic diagnoses (\%) of the patients who underwent laparoscopy or laparotomy. 


\begin{tabular}{l|c|c|c}
\hline Pathologic diagnosis & lap $(\mathrm{n}=78)$ & $\mathrm{LAT}(\mathrm{n}=56)$ & Total(n=134) \\
\hline Mature cystic teratoma & $27(34.6)$ & $19(33.9)$ & $46(34.3)$ \\
\hline Corpus luteum & $18(23.1)$ & $9(16.1)$ & $27(20.1)$ \\
\hline Mucinous cystadenoma & $4(5.1)$ & $6(10.7)$ & $10(7.5)$ \\
\hline Endometriosis & $3(3.8)$ & $1(1.8)$ & $4(3.0)$ \\
\hline Serous cystadenoma & $5(6.4)$ & $4(7.1)$ & $9(6.7)$ \\
\hline Paraovarian cyst & $8(10.3)$ & $7(12.5)$ & $15(11.2)$ \\
\hline Follicular cyst & $1(1.3)$ & $1(1.8)$ & $2(1.5)$ \\
\hline Paratubal cyst & $4(5.1)$ & $1(1.8)$ & $5(3.7)$ \\
\hline Malignant mass & & & $2(1.5)$ \\
\hline Borderline mucinous mass & 0 & $2(3.6)$ & $1(0.7)$ \\
\hline \multicolumn{1}{c|}{ Borderline serous mass } & 0 & $1(1.8)$ & 0 \\
\hline \multicolumn{1}{c|}{ Invasive serous mass } & 0 & & $2(1.5)$ \\
\hline Mucinous adenocarcinoma & 0 & & 0 \\
\hline Endometriod adenocarcinoma & & & 0 \\
\hline Not determined $\dagger$ & $8(10.3)$ & $3(5.3)$ & $8(6.0)$ \\
\hline
\end{tabular}

†Tissue of adnexal masses was not obtained during operations including release of the torsion, or exploration of pelvic cavity.

\section{Supplementary Files}

This is a list of supplementary files associated with this preprint. Click to download.

- renamed88d8e.pdf 